\title{
Remote-control Heating Device for Improving Electric Vehicle's Winter Endurance Ability
}

\author{
Yang Yuxin \\ North China Electric Power University, China \\ 13941978694@163.com
}

Keywords: electric vehicle battery heating, air conditioning heating, remote control, charging and discharging performance, endurance

\begin{abstract}
A remote heating control device is designed to improve the winter endurance of electric vehicles. The main purpose of this device is to overcome the disadvantages of electric cars such as obvious reduction of battery life range and inconvenient heating control in winter due to the decrease of temperature, the decrease of battery activity, and the large amount of electric energy needed for heating air conditioning. When the car is connected to the charging pile, the battery heating system and air conditioning of the electric car can be remotely controlled by SMS, and the energy of the charging pile can be consumed for heating, so as to solve the problem of significantly reducing the driving range of electric cars in winter.
\end{abstract}

\section{Development background and significance}

With the increase of energy consumption and the serious environmental pollution, electric cars are getting more and more attention. However, when they are used in winter, the range of electric cars decreases significantly. In winter, when the ambient temperature decreases, the active substances in the anode and cathode materials of lithium battery decrease, the viscosity of electrolyte decreases, and the discharge capacity decreases. Take lithium iron phosphate, currently the most common compound in lithium batteries, for example. At minus 20 degrees Celsius, discharge capacity is reduced by nearly $50 \%$. Therefore, the battery needs to be heated in advance to restore its endurance.

At present, common heating elements include variable resistance heating elements (namely PTC) and constant resistance heating elements. PTC has a large volume, which increases the original volume of electric vehicles. Therefore, PI film is used as heating element. PI film is welded by polyimide film electric heater and conductor. Polyimide film is used as electrical insulation material and copper-nickel foil or copper-nickel wire is used as electrothermal material. ${ }^{[1]}$ The thickness of PI film is only $0.2 \mathrm{~mm}$, greatly reducing the volume. ${ }^{[2]}$

Electric vehicles use air conditioning to heat in winter, and the demand for electricity is large, which also causes the mileage to decrease. In order to comprehensively solve the above problems, when the electric vehicle is connected to the charging pile, the remote control opens the battery and the air conditioning heating system, effectively increasing the subsequent flight mileage of the power failure, increasing the tolerance of the electric vehicle to the temperature, and contributing to the electric vehicle more deeply. Replace traditional energy vehicles.

\section{Design scheme}

2.1 The whole device is mainly divided into control system and heating system. The control system consists of GSM module, STM32 MCU, relay and DS18B20 temperature sensor. The heating system is divided into battery heating system and interior air conditioning heating system. The heating circuit of the battery includes transformer, polyimide heating film and LED light belt. The heating circuit of interior air conditioning is simulated by fan and transformer.

In the battery heating system, the user sends a text message "START" to the GSM module 
pre-installed number, remotely turns on the preheating heating mode, and simultaneously replies to the message "ALREADY BEGUN" to inform the user that the work has started. When the temperature reaches $0{ }^{\circ} \mathrm{C}$, the MCU controls the relay and automatically switches the heating gear to the drive heating mode. When the temperature reaches $25^{\circ} \mathrm{C}$, the heating system is automatically turned off and the message "FINISH" is returned to inform the end of the heating process. When the temperature is lowered to $20^{\circ} \mathrm{C}$, the system automatically turns on the insulation mode and reheats the battery. In the heating process, the text message "TELL" can be sent in real time to inquire about the heating situation. After the system obtains the temperature information, the system automatically responds to the corresponding temperature range and the feedback mechanism is set to facilitate dynamic monitoring of the heating situation and insight into the system operation. In the air conditioning heating system in the car, the principle is similar to the battery heating system. The user sends a text message "AC" (air conditioner) to the GSM module pre-installed number, and the air conditioning heating system is turned on. The system uses the charging pile to heat the air conditioner and improve the interior. After the temperature reaches $23^{\circ} \mathrm{C}$, the message "ALREADY" is sent back to inform the user that they can get on the bus.

In order to more intuitively observe the opening and closing of the battery heating system, an LED strip is installed outside the model. When working in the preheating heating mode, the yellow light is observed. When driven in the driving mode, the red light is on; When the heating is turned on, the green light is on.

\subsection{Control system}

The control system of this design is mainly composed of GSM module, STM32 single chip microcomputer, DS18B20 temperature sensor and three-way relay.

The working principle of the battery heating control system is: first initialize after power-on, and the low-level outputs of the single-chip microcomputers PA8 and PD2. The GSM module communicates with the MCU through the AT command. The MCU continuously sends the AT command to the GSM module through the serial port 2: $A T+C M G R=<$ message number $>$, when the read message content is "START", the MCU controls the IO. Port PD2 outputs a high level, triggers the relay, and turns on the preheating heating system. The DS18B20 temperature sensor continuously reads the battery temperature after starting. When the read temperature is equal to $0{ }^{\circ} \mathrm{C}$, the PD2 port of the single-chip microcomputer outputs a low level, and the PA8 port outputs a high level, and the heating system is switched to drive heating. When the temperature is equal to $25^{\circ} \mathrm{C}$, the single-chip microcomputer PA8 outputs a low level, and the heating ends. When the temperature drops to $20^{\circ} \mathrm{C}$, the single-chip PD2 outputs a high level, and the insulation system is turned on to keep the battery warm.

The working principle of the air conditioning heating system is: after starting up and the heating control system is initialized at the same time, the single chip PC1 outputs a low level. When the short message content "AC" is read, PC1 outputs a high level, triggering a relay connected to the fan, and when the temperature sensor reads the temperature at $23^{\circ} \mathrm{C}$, the air conditioning heating system stops working.

\subsection{Heating system}

The battery heating system is divided into two modes: preheating heating and driving heating. It consists of a transformer, a polyimide electric heating film, and an LED strip. The transformer converts $220 \mathrm{~V}$ AC into $12 \mathrm{~V}$ and $24 \mathrm{~V}$ DC, respectively, and supplies power to the heating film and the lamp strip. When the preheating heating is started, the transformer outputs $12 \mathrm{~V} \mathrm{DC}$, the yellow light is on, the heating film starts to heat, and the heating power is $30 \mathrm{~W}$; when the driving heating is started, the transformer outputs $24 \mathrm{~V}$ DC, the yellow light is off, the red light is on, and the heating power is $70 \mathrm{~W}$.

The device uses a rectangular parallelepiped lithium iron phosphate battery for experiments, using a heating film to heat the side of the battery, heating the battery, and observing the temperature change. The heating film is fully adhered to the two largest sides of the battery, and the heat is directly transmitted through the heating film to achieve heating of the battery. 
The air conditioning heating system in the car is simulated by a transformer and a fan, and the air conditioner is simulated by a fan.

\section{Effect and application prospect analysis}

After heating the lithium iron phosphate battery with a heating film, the battery activity is significantly improved, and the lower the temperature, the more obvious the lifting effect. The heating battery has an improved charging performance. The temperature is lower than $-20^{\circ} \mathrm{C}$, the lithium battery charging available capacity ratio is 0 , the temperature rises to $10^{\circ} \mathrm{C}$, and the available capacity ratio is increased to $90.11 \%$.

At the same time, low-temperature charging has the safety hazard of battery explosion. Heating the battery not only saves energy, improves charging and discharging performance, increases cruising range, but also improves the safety factor of electric vehicles in winter.

A large part of the existing electric vehicle heating mode is that the electric vehicle is heated after being inserted into the charging pile, which wastes electric energy, and the heating for a long time causes great damage to the performance of the battery. The electric vehicle battery/air-conditioning heating remote control device of this project can improve the tolerance of pure electric vehicles to temperature changes, expand the temperature range of pure electric vehicles, and help pure electric vehicles to replace traditional energy vehicles more deeply, thus reducing automobiles. The pollution of the exhaust emissions to the environment.

\section{References}

[1] Peng Fanghan, Yin Yazhou, Yan Liwei et al. Experimental study on high temperature resistance of polyimide film-type electric heating circuit [J]. Spacecraft Environmental Engineering, 2014, 31(1): 42-46.

[2] Pan Chengjiu, Guo Hongfei. Research on insulation and heating of electric vehicle battery pack [C]// Proceedings of the 2013 Annual Meeting of China Automotive Engineering Society. 2013. 